Trabajos y Comunicaciones, 2da. Época, Nº 45, e030, marzo 2017. ISSN 2346-8971

Universidad Nacional de La Plata.

Facultad de Humanidades y Ciencias de la Educación.

Departamento de Historia

\title{
Tras las huellas de los jesuitas en las pampas argentinas. La reducción "Nuestra Señora de la Purísima Concepción de los Indios Pampas" (1740-1753)
}

\author{
Searching Jesuit's footsteps in the Argentinean pampas: the \\ mission "Nuestra Señora de la Purísima Concepción de los Indios \\ Pampas" (1740-1753)
}

\section{Victoria Pedrotta *}

* Universidad Maimónides, Centro de Estudios Biomédicos, Biotecnológicos, Ambientales y de Diagnóstico, CONICET, Universidad Nacional de La Plata, Argentina $\perp$ vpedrotta@conicet.gov.ar

\section{PALABRAS CLAVE}

Reducción Jesuita

Siglo XVIII

Región Pampeana

Arqueología

\section{KEYWORDS}

Jesuit mission

XVIIIth century

Argentinean pampas

Archaeology

\section{RESUMEN}

En mayo de 1740 los jesuitas Querini y Strobel fundaron la reducción "Nuestra Señora de la Purísima Concepción de los Indios Pampas", en la desembocadura del río Salado, en la pampa argentina, iniciando así un ambicioso proyecto evangelizador destinado los grupos indígenas pampeano-patagónicos. A los pocos años, dicha reducción tuvo que trasladarse a un paraje cercano, donde se estableció hasta 1753. En este trabajo se presentan los resultados del análisis de la base documental recabada en el marco de las investigaciones arqueológicas que comenzamos en 1998, centrado en aspectos referidos al entorno geográfico de la reducción, su núcleo de población inicial, edificaciones y trazado, a la vez que se discute la información acerca de la localización actual de los dos asentamientos que consecutivamente la conformaron.

\section{ABSTRACT}

In may 1740, Jesuits Querini and Strobel started the mission "Nuestra Señora de la Purísima Concepción de los Indios Pampas”, at the mouth of the Salado River in the Argentinean pampas, thus beginning an ambitious evangelizer project for the indigenous groups that inhabited in the Pampa and Patagonia lands. Within a few years, the new town had to be moved to a nearby site, where settled until 1753. This paper presents the analysis of the document database collected in the context of archaeological investigations that we began in 1998, focused on aspects related to the mission geographical environment, its initial population, buildings and layout, as well as the information about the current location of the two settlements that consecutively formed it. 


\section{Introducción $\underline{1}$}

A mediados del siglo XVIII, la Corona Española decidió encomendar a la Compañía de Jesús la evangelización de las sociedades indígenas que habitaban en la región pampeana por medio de su reducción en pueblos, sistema que dicha orden religiosa estaba desarrollando exitosamente con muchas otras poblaciones originarias de la entonces llamada Provincia del Paraguay, además de contar con una amplia experiencia a lo largo de más de dos siglos y medio en el campo misional. Luego de las pertinentes gestiones ante las autoridades coloniales y de negociar con los caciques que lideraban algunos grupos indígenas que se encontraban relativamente próximos a Buenos Aires, en mayo de 1740 los padres Manuel Querini y Matías Strobel dieron inicio a este proceso con la fundación del pueblo que llamaron Nuestra Señora de la Purísima Concepción de los Indios Pampas, cerca de la desembocadura del río Salado, en el actual partido bonaerense de Castelli. A los pocos años, este primer asentamiento misional tuvo que ser trasladado a un paraje cercano, donde se estableció hasta febrero de 1753.

Para fines de 1747, luego de realizar sendos viajes exploratorios, los padres Tomás Falkner y Joseph Cardiel fundaron otras dos misiones en la región pampeana: la misión Nuestra Señora del Pilar del Volcán, en el extremo oriental del sistema serrano de Tandilia, a la que se sumó en 1750 la misión Nuestra Señora de los Desamparados, cuya ubicación aún se desconoce, si bien las crónicas refieren que ambas distaban cuatro leguas entre sí (Sánchez Labrador, [1772] 1936, p. 124-125). Las dos últimas fueron desalojadas en 1751 ante las hostilidades de algunos grupos indígenas que estaban liderados por el cacique Bravo, debiendo retirarse los misioneros con parte de los catecúmenos a la reducción Nuestra Señora de la Concepción de los Indios Pampas, donde permanecieron hasta que se produjo su abandono definitivo. Sobre la historia de estas reducciones pueden consultarse Dobrizhoffer (ca.1767-1797, editado en 1967); Furlong (1938); Moncaut (1981); Pastells (1948); Page (2012) y Sánchez Labrador (1772), reeditado en 1936.

Indudablemente el sistema reduccional jesuítico ocupó un lugar de preeminencia en la historia de las relaciones interétnicas de la Gobernación del Río de la Plata y el Paraguay durante el Período Colonial, llegando a constituir sus "pueblos de indios" de la Provincia del Paraguay verdaderos núcleos urbanos y centros pioneros en lo que respecta al desarrollo económico, cultural y artístico (Maeder, 1999; Viñuales, 2007). El crecimiento y esplendor alcanzado por los 30 pueblos guaraníes para las primeras décadas del siglo XVIII representa emblemáticamente los ideales espirituales y materiales perseguidos por la Compañía de Jesús, que luego buscaron extender a otros confines del pretendido dominio español, incluyendo a las naciones indígenas que habitaban las regiones pampeano-patagónicas. Ciertamente, las fronteras australes conformaron un espacio marginal, no sólo con respecto a la administración central de dicha orden religiosa sino también dentro de su proyecto evangelizador de los numerosos pueblos indígenas de esa vasta región del imperio hispano. En este contexto, las tres reducciones que se fundaron en la pampa húmeda, dentro del actual territorio de la provincia de Buenos Aires, tuvieron efímera duración y resultados adversos, siendo generalmente relegadas a un papel menor dentro de la historia de la labor misional y la obra evangelizadora jesuítica.

Recientemente se han producido avances significativos, tanto en el conocimiento general de "las otras reducciones” no guaraníes de la Provincia del Paraguay (Page, 2012) -que comprenden las iniciativas misionales en la pampa bonaerense-, como en lo que hace a ciertos aspectos particulares 
de estas últimas. Así, se han publicado trabajos enfocados hacia la geopolítica del imperio español, sus instituciones coloniales y sus estrategias de expansión territorial (Martínez Martin, 1994; Tejerina, 1996). También se han analizado los motivos del poco éxito de la empresa jesuita en el marco de los ciclos de conflictos interétnicos y los cambios coyunturales en la política de fronteras (Zapico, 1994; Iglesias, 2000); se ha indagado el funcionamiento y la dinámica interna de las reducciones así como los cambios sociales, económicos y políticos que supusieron para las poblaciones indígenas locales (Bohn Martins, 2014; Hernández Asencio, 2003); en tanto, otros estudios han buscado aproximarse al tema desde la perspectiva indígena, tratando de comprender las lógicas a partir de la cuales los caciques y grupos involucrados se relacionaron con los misioneros y participaron estratégicamente de la experiencia reduccional (Irurtia 2007, 2008; Néspolo, 2007).

Diversos historiadores y antropólogos han estudiado, desde diferentes perspectivas y objetivos, una multitud de aspectos desplegados en torno a la génesis, el funcionamiento y el desenlace de las tres reducciones jesuitas bonaerenses, pero resulta muy escaso el desarrollo de investigaciones arqueológicas sistemáticas en las mismas. Ello obedece a una variedad de factores que van desde conflictos legales por el acceso a los predios para llevar a cabo los trabajos de campo necesarios (Pedrotta, 2011, 2013), hasta las dificultades técnicas para hallar los restos materiales de ocupaciones tan breves como fue el caso de la misión Nuestra Señora de los Desamparados. El presente artículo se centra en el estudio del contexto en el cual se produjo la fundación, el posterior traslado y el abandono final de la reducción Nuestra Señora de la Concepción de los Indios Pampas, que fue la primera población española fundada al sur del río Salado, en tierras que entonces formaban parte del territorio explotado, habitado y controlado por las sociedades indígenas de la región pampeana y el norte de la Patagonia, como ya se señaló.

Para ello, se sintetizan y analizan los datos que se han recabado -tanto en fuentes documentales y cartográficas inéditas como en la bibliografía publicada- sobre el entorno geográfico y las particularidades ambientales del lugar donde se fundó la misión, la composición de su población inicial, así como las características arquitectónicas de las edificaciones que la integraron. Por cierto, algunos de esos aspectos han sido tocados parcialmente en los trabajos antes mencionados, pero ninguno de ellos se planteó entre sus objetivos determinar la ubicación precisa y actual de la reducción en el terreno, cuestión que resulta crucial para las pesquisas arqueológicas.

De este modo, revisitamos tanto las fuentes como la producción historiográfica previa, partiendo de una mirada arqueológica centrada en la dimensión material de los procesos, con preguntas orientadas a la comprensión de la materialidad de la reducción en el pasado y su proyección en el presente. Las fuentes documentales provienen del Archivo General de Indias de Sevilla, España (AGI), copias de Documentos del Archivo General de Indias que se encuentran en la Biblioteca del Museo Etnográfico “J. B. Ambrosetti” de la Facultad de Filosofía y Letras de la Universidad de Buenos Aires (AGI en ME) y del Archivo General de la Nación Argentina (AGN).

En este marco, se discuten algunas hipótesis acerca de su primer emplazamiento, así como la localización actual del lugar donde el pueblo debió ser trasladado a los pocos años de su primera fundación. Cabe aclarar que las distintas fuentes de información presentadas integran el corpus empírico documental generado en relación con las investigaciones arqueológicas que venimos 
desarrollando en esta reducción (Pedrotta, 2015).

\section{Fuentes documentales y obras de referencia}

Las fuentes inéditas que han sido consultadas provienen del Archivo General de la Nación Argentina, Sala IX y Documentos de la Biblioteca Nacional, del Archivo General de Indias de Sevilla y copias de Documentos del Archivo General de Indias que se encuentran en la Biblioteca del Museo Etnográfico “J. B. Ambrosetti” de la Facultad de Filosofía y Letras de la Universidad de Buenos Aires, en Argentina. En la mayor parte de los casos, se trata de correspondencia entre las autoridades civiles y eclesiásticas, seguida de algunos registros administrativos y de correspondencia entre los padres que estuvieron a cargo de las tres reducciones bonaerenses y otros religiosos que contemporáneamente desempeñaban distintos cargos en la estructura de la Compañía de Jesús. También fueron consultadas las cartas y planos inéditos que se hallan en dichos repositorios, junto a los mapas que acompañan los duplicados de diligencias de mensura de las fracciones del terreno que corresponden a la antigua estancia de la reducción De la Concepción, que comprenden desde fines del siglo XVIII hasta la primera mitad del XIX y que se encuentran en el Archivo Histórico de la Dirección de Geodesia, Ministerio de Infraestructura de la Provincia de Buenos Aires, en Argentina.

Las fuentes documentales jesuitas editadas comprenden básicamente: 1) las Cartas Anuas del período 1735-1743, que fueron escritas por el padre Pedro Lozano y posteriormente fueron traducidas del latín y publicadas por el padre Carlos Leonhardt (1924a, 1924 b); 2) los diarios, mapas y monografías elaborados por Joseph Cardiel ([1748] 1930; [1747] 1940; [1747] 1956; [1771] 1994); 3) la conocida obra del padre Tomás Falkner ([ca. 1774] 1974); 4) las monografías de los religiosos Martín Dobrizhoffer ([ca.1767-1797] 1967) y Joseph Sánchez Labrador ([1772] 1936), esta última enteramente dedicada, a modo de crónica y síntesis etnográfica, a las reducciones de la región pampeana.

Esta variada y numerosa cantidad de escritos, y principalmente la cartografía producida por los integrantes de la Compañía de Jesús, se inscriben en una estrategia de acción sobre el espacio que fue desplegada como una parte fundamental de su acción evangelizadora (Barcelos, 2010) y ha sido revalorizada como una de las fuentes esenciales en las que se cimentó el conocimiento geográfico, ecológico y etnográfico de vastas extensiones que conformaban las fronteras australes del imperio español. Asimismo, fueron las primeras en integrar explícitamente el saber espacial que les iba siendo provisto por los pueblos originarios con quienes interactuaron (de Lasa y Luiz, 2011).

Como bien notan de Lasa y Luiz (2011, p. 11) la actividad cartográfica de los jesuitas tuvo "un doble propósito político institucional y práctico” vinculado, por un lado, con el interés de la orden en justificar los emprendimientos misionales en territorios lejanos que resultaban poco atractivos para los europeos y resolvió, por otro lado, “problemas de índole espacial con vistas a la instalación de misiones en un ámbito desconocido y controlado por la población indígena”.

Las reducciones bonaerenses son un buen ejemplo de ello, ya que los padres J. Cardiel y T. Falkner, quienes elaboraron los principales mapas de las regiones pampeano-patagónicas del siglo XVIII, con referencias precisas sobre los recursos naturales, la red hidrográfica, asentamientos y rutas 
indígenas y puntos estratégicos para el control del territorio (de Lasa y Luiz, 2011, p. 19), fueron protagonistas directos: ambos vivieron temporariamente en la reducción Nuestra Señora de la Concepción y realizaron viajes entre ésta y la misión Nuestra Señora del Pilar del Volcán, así como distintas exploraciones hacia el interior de la pampa húmeda durante los cuales establecieron contacto con grupos étnicos diversos. Joseph Cardiel hizo una larga expedición por el litoral marino bonaerense que documentó en su "Diario del viaje y Misión al Río del Sauce” de 1748, además de otros viajes cortos en los que exploró parcialmente el sistema de Tandilia. En una de sus estadías en la "Sierra del Volcán”, por ejemplo, este jesuita entabló contacto con veinte o treinta "toelchus del Rio del Sauce”, los cuales habían ido allí a cazar yeguas cerriles en el año 1748 (Cardiel, [1747] 1956, p. 161).

Es de destacar que, según el estudio crítico efectuado por Outes (1930), esa partida indígena procedía del actual río Negro. El padre T. Falkner, a su vez, llevó a cabo viajes a la zona del cabo San Antonio, a distintos sectores de Tandilia y del litoral marino oriental entre 1744 y 1750 . Este misionero reconoce como sus fuentes principales de información relatos de los indígenas y los cautivos con quienes trató en esas oportunidades, entre los que se destaca el cacique Cangapol (o Bravo, como lo llamaban los españoles) y un cautivo llamado Mansilla que había estado seis años entre los «tehuelhets» (Falkner, [ca. 1774] 1974, p. 53-54). Los padres Lozano, Dobrizhoffer y Sánchez Labrador, por su parte, fueron contemporáneos y compañeros de la misma orden religiosa, tratándose de fuentes indirectas en lo que atañe a las reducciones bonaerenses.

Adicionalmente se utilizó un conjunto de bibliografía que trata en forma general la experiencia misional jesuítica en la región pampeana desde el campo de la historia y la antropología, tales como los artículos de Martínez Martin (1994), Zapico (1994), Tejerina (1996), Jones (1999), Iglesias (2000), Hernández Asencio (2003), Irurtia (2007, 2008), Néspolo (2007), Bohn Martins (2014), la tesis doctoral de Arias (2006), la obra clásica del padre Furlong (1938), el libro ya citado de Page (2012), así como el libro publicado por un estudioso local, Carlos Moncaut (1981), que aborda específicamente el caso de la reducción Nuestra Señora de la Concepción de los Indios Pampas. Además fueron de gran valor los estudios críticos que han sido realizados por Outes (1930) y Furlong (1940) y por Canals Frau (1974) sobre las obras de los padres Cardiel y Falkner, respectivamente. Son destacables también las contribuciones tradicionales de Furlong (1936) y Martínez Sierra (1975) acerca del desarrollo de la cartografía en la región pampeana y los aportes más recientes de Barcelos (2000, 2010) y de Lasa y Luiz (2011), que proponen abordajes críticos a la producción cartográfica de los jesuitas entendida como parte de las estrategias de acción de la Orden sobre el espacio no incorporado al dominio colonial español. Estos últimos, en particular, efectúan consideraciones relevantes acerca de la condiciones de producción de los mapas de dichos misioneros que fueron consultados para este trabajo.

Como referentes complementarios en relación con los circuitos comerciales de intercambio intra e inter-étnicos entre los indígenas pampeano y los centros hispano-criollos del período Colonial, tomamos a Palermo (1991, 2000), Mandrini (1993, 1994), León Solís (1987, 1989/1990), Crivelli (1994, 1997), así como a Nacuzzi, Lucaioli y Nesis (2008), entre otros. Se consultó el trabajo del padre M. Hux (1993) con respecto a la biografía de algunos de los caciques que participaron de la experiencia misional. Con respecto a las denominaciones, se optó por respetar los modos en que 
fueron nombrados los individuos y/o grupos indígenas por quienes produjeron las fuentes documentales, apenas como una forma de identificar y organizar la alteridad que suponen los encuentros interétnicos; suscribimos al concepto no esencialista de «identidades impuestas» propuesto por Nacuzzi (1998) y sabemos que se trata de apelativos dinámicos, que eran estratégicamente empleados por unos y otros en las situaciones de contacto cultural.

\section{Una compleja coyuntura para dar inicio a la Misión de los Pampas}

A medida que avanzaba el siglo XVIII en la campaña bonaerense comenzó a hacerse notoria la disminución del ganado cimarrón, del cual se abastecían tanto la sociedad hispano-criolla como los indígenas pampeano-patagónicos y otros grupos nativos de ambas vertientes de la cordillera andina. De forma paralela a la merma de los rodeos vacunos aumentaba su demanda, que era impulsada, entre otros factores, por una recomposición demográfica de las sociedades indígenas locales en la región pampeana, a lo que deben sumarse aquellos grupos que migraron en el marco del proceso de araucanización, así como la demanda sostenida de los mercados transandinos (Coni, 1979, p. 30-31; Crivelli, 1994, p. 14; Palermo, 1991, 2001). Todos estos elementos influyeron en la creciente tensión entre españoles e indígenas sobre el acceso y explotación del ganado cimarrón, intensificándose por parte de estos últimos los robos a estancias y poblados de los primeros, junto a los asaltos a las tropas de carretas y los comerciantes que transitaban por la región y sus adyacencias (Mandrini, 1993).

Las respuestas del gobierno colonial fueron múltiples y oscilaron entre la gestión de tratados de paz con los grupos menos hostiles, la realización de expediciones punitivas, la formación de un sistema defensivo más estable que los cuerpos de milicias y la concreción de emprendimientos misionales que ya habían sido propuestos por la Compañía de Jesús y autorizados por la corona desde el último cuarto del siglo anterior (Iglesias, 2000; Martínez Martín, 1994; Page, 2012). Según las autoridades eclesiásticas, las misiones debían lograr “el bien espiritual, que se seguirá a los Indios, y Gloria de Dios” (AGI en ME, Doc. I.19, expediente iniciado por el Procurador General de la Provincia del Paraguay, P. J. J. Rico, 1743), objetivo evangelizador al que se sumaba una cuestión de gran importancia para la geopolítica colonial española: el resguardo efectivo de la extensa costa patagónica y sus habitantes de las ambiciones de otras potencias coloniales (Bohn Martins, 2014; Martínez Martín, 1994; Page, 2012; Zapico, 1994). $\stackrel{2}{*}$ Paralelamente, durante la década de 1750 se organizaron los batallones de Blandengues, articulándose una incipiente línea defensiva en torno a la instalación de fuertes y fortines (ver Marfany, 1940).

En este contexto se decidió la instalación de una reducción entre los grupos "pampas” y "serranos” que habitaban las tierras más cercanas a la jurisdicción de Buenos Aires. Según planeaba el padre Joseph Rico, Procurador General de la Provincia del Paraguay, en 1743, esa primera misión iba a convertirse en el "camino y entrada a los Patagones, y demás Naciones de Indios (...) hasta el Estrecho de Magallanes”, a la vez que la población indígena allí reducida debería servir como una suerte de "centinelas avanzadas, que den anticipados avisos de los movimientos de los Serranos, y demás naciones infieles, que (...) hostilizan de tiempo en tiempo aquellas campañas” (AGI en ME, Doc.19, expediente iniciado por el Procurador General de la Provincia del Paraguay, P. J. J. Rico, 1743). Así, se pretendía que los emprendimientos misionales favorecieran la pacificación de la 
campaña, no sólo en forma directa por medio de la sujeción y control de los grupos más próximos a los poblados hispano-criollos, sino también funcionando como "reparo de las invasiones de los infieles enemigos y peguenches y Serranos”, es decir, como una defensa ante posibles ataques de otras agrupaciones más lejanas (AGI en ME, Doc. I.11, expediente iniciado el 7-9-1740).

La empresa reduccional recién pudo concretarse luego de una década de episodios de creciente hostilidad entre los españoles y algunos grupos indígenas, que culminó con el gran malón a Magdalena de 1740 encabezado por el cacique Cangapol o Bravo -como era nombrado por los españoles- en represalia por la muerte del cacique Tomilchi Ya que había acaecido previamente (Crivelli, 1994, p. 17; Jones, 1999, p. 160; Leonhardt, 1924a, 1924b; Marfany, 1940; Moncaut, 1981). La trayectoria del linaje Cangapol, protagonistas clave del liderazgo indígena a mediados de la centuria y sus vínculos políticos y económicos tanto inter-értnicos como intra-étnicos, han sido objeto de análisis por parte de Néspolo (2007), Irurtia (2008) y Arias (2011/2012), por lo que no nos detendremos aquí sobre ellos. No obstante, vale hacer un breve repaso de los hechos centrales en esta coyuntura conflictiva. Con el argumento de hallarse la ciudad de Buenos Aires:

"De algunos años a esta parte repetidas veces hostilizada en sus estancias de los indios infieles que llaman Serranos con muertes de sus vecinos y robos de considerables porciones de ganados, que atemorizada ya la vecindad han desalojado sus posesiones y criaderos (...) como por las muertes y robos que han hecho en diferentes años en los caminantes a la provincia de Cuyo y a la ciudad de Cordoba de la del Tucumán” (AGI en ME, Doc. I.9., carta de la ciudad de Buenos Aires al rey del 21-10-1739).

Se decidió entonces realizar una gran expedición punitiva que fue costeada por los propios vecinos. Así, en 1739 partió con rumbo a las Salinas Grandes un contingente de 1000 vecinos y 50 presidiarios al mando del maestre de campo Juan de San Martín, quien paralelamente despachó partidas en busca de indígenas al Casuatí -como entonces se llamaba al sistema serrano de Ventania, ubicado al sudeste de la pampa húmeda- y al primer cerro de Tandil (en el extremo oriental del sistema serrano de Tandilia), donde mataron a un grupo de indígenas desarmados. A su regreso, los expedicionarios pasaron por el paraje “del Carbón” en el río Salado, sitio en el cual estaba instalado con sus toldos el cacique pampa serrano Tolmichi Ya. Falkner ([ca. 1774] 1974, p. 132), no obstante, señala que Tomilchi Ya o Maximiliano era "un cacique Tehuel", primo de Cangapol.

En cualquier caso, pese a las relaciones amistosas que dicho cacique mantenía con las autoridades coloniales y a la licencia que le había sido otorgada por el gobernador Miguel de Salcedo para instalarse allí, él mismo fue ferozmente atacado, sus hombres fueron asesinados y las mujeres y los niños apresados (Falkner [ca. 1774] 1974, p. 132; Leonhardt, 1924a, p. 299). Este hecho, sumado a la enemistad existente entre los "pampas” más “domésticos” (como entonces se solía designar a aquellos grupos cercanos a Buenos Aires, sus chacras y estancias contiguas, con cuyos vecinos habían establecido relaciones de carácter laboral y comercial, principalmente) y los “serranos”, que ocasionaba que los primeros se vieran rodeados por dos frentes de conflicto, impulsó a algunos caciques pampas a pedir protección al gobierno colonial a comienzos del año 1740 (Cardiel, [1747] 1940; Leonhardt, 1924a, p. 299; Sánchez Labrador, [1772] 1936, p. 82-84). El gobernador les prometió paz y la protección del rey, poniendo como condición que aquellos aceptaran reducirse en 
un pueblo y que se instruyeran en la religión cristiana (AGI en ME, Doc. I.11, expediente iniciado el 7-9-1740).

Luego de las respectivas consultas con el Cabildo de Buenos Aires, que figuran en los Acuerdos del Extinguido Cabildo de Buenos Aires (serie II, tomo VIII, págs. 123-125), fueron aceptados los requerimientos que había impuesto la Compañía de Jesús, como consta en el legajo 62 de las consultas de los Colegios de Jesuitas conservados en el Archivo General de la Nación. Al respecto, cabe notar que Martínez Martín (1994, p. 150-152) hizo un interesante análisis de las condiciones impuestas por los jesuitas, en tanto Page (2012, p. 384-391) indagó acerca de las gestiones de los Procuradores de la Orden ante la corona y las autoridades locales. En este marco, se emprendió la búsqueda del emplazamiento adecuado, por un lado y, por otra parte, la recolección de limosnas por la ciudad y el vecindario a fin de solventar los gastos que demandara la primera etapa de fundación de la reducción (Leonhardt, 1924b, p. 371-372; Leonhardt, 1924c, p. 441; Sánchez Labrador, [1772] 1936, p. 84).

Según han remarcado varios investigadores, esta compleja coyuntura evidencia la capacidad estratégica que tuvieron ciertos caciques para lograr beneficios a partir de la instalación de las misiones, tales como la protección ante los conflictos intra-étnicos, el reparo ante las hostilidades hispano-criollas, el acceso a bienes no producidos en las tolderías, la instalación de centros multiétnicos de intercambio de bienes materiales y de circulación de información, la existencia de espacios "híbridos" y de mediación intercultural, entre otras cuestiones (Bohn Martins, 2014; Hernández Asencio, 2003; Irurtia, 2008; Néspolo, 2007).

\section{¿Dónde, cómo y quienes construyeron la reducción?}

Matías Strobel y Manuel Querini fueron los jesuitas inicialmente encargados de crear la primera de las misiones australes. El padre Strobel, quien venía de siete años al frente de la reducción guaraní De Jesús y fue elegido porque “era el único que sabía la lengua”, tuvo a su cargo la tarea de encontrar el lugar adecuado para el futuro pueblo. Así consta en el libro de consultas de los Colegios de Jesuitas -folio 130- que fue transcripto por Sánchez Labrador ([1772] 1936, p. 224).

El requisito más importante que debía cumplir este paraje era el estar lo suficientemente alejado de las poblaciones españolas, de modo tal de impedir el trato entre éstas y los catecúmenos reducidos, cuyos efectos negativos conocían sobradamente los jesuitas debido a su gran experiencia misional en otras regiones (Cardiel, [1771] 1994; Furlong, 1938; Leonhardt, 1924b, p. 372; Sánchez Labrador, [1772] 1936). Finalmente, junto con un grupo de caciques y una escolta de soldados, Strobel optó por elegir un lugar que distaba de Buenos Aires "unas cuarenta leguas (...) a lo largo del océano Atlántico, a $36^{\circ}$ de latitud”, según relata el mismo en una carta que escribió pocos meses después (carta de Strobel del 3-10-1740, reproducida en Leonhardt, 1924c, p. 442). Este sitio se encontraba "A la otra banda del río Salado, inmediato a la desembocadura del río de la Plata en el mar, junto al cabo de San Antonio” (Sánchez Labrador, [1772] 1936, p. 84-85).

Las características fisiográficas de ese sector, que integra el Área de la Depresión del Salado, se distinguen por conformar un entorno de llanuras bajas, lagunas y cursos de agua temporarios y permanentes que circundan la actual bahía de Samborombón. La disposición de la red hidrográfica 
modela ahí una «rinconada» natural, que resultaba óptima para la captura y la guarda de la futura hacienda que iba a abastecer el pueblo. La utilidad de este rasgo geográfico es destacada reiteradamente, tanto en las fuentes cartográficas consultadas como en dos crónicas contemporáneas alusivas. La primera de dichas crónicas es el detallado relato que hizo Sánchez Labrador ([1772] 1936, p. 84-85) acerca de los comienzos de la misión de los pampas: "Hallóse también campo proporcionado, en que poner el ganado, y establecer la Hacienda. Era este campo una rinconada de tierra bien capaz, que forma con el mar el río Salado”. La segunda crónica corresponde también a un jesuita coetáneo, el padre Lozano, quien describía el lugar en estos términos: "Hacia el oriente se divisa la mar, hacia el norte el río Salado, y entre este río y la reducción y el mar se extienden los campos donde pastean (...) millares de vacas” (Leonhardt, 1924b, p. 372-373), destacando la cantidad de cabezas de ganado vacuno que conformaban la hacienda del pueblo.

Figura 1. Localización de la reducción Nuestra Señora de la Purísima Concepción de los Indios Pampas (1740-1753) en el mapa actual de la provincia de Buenos Aires.

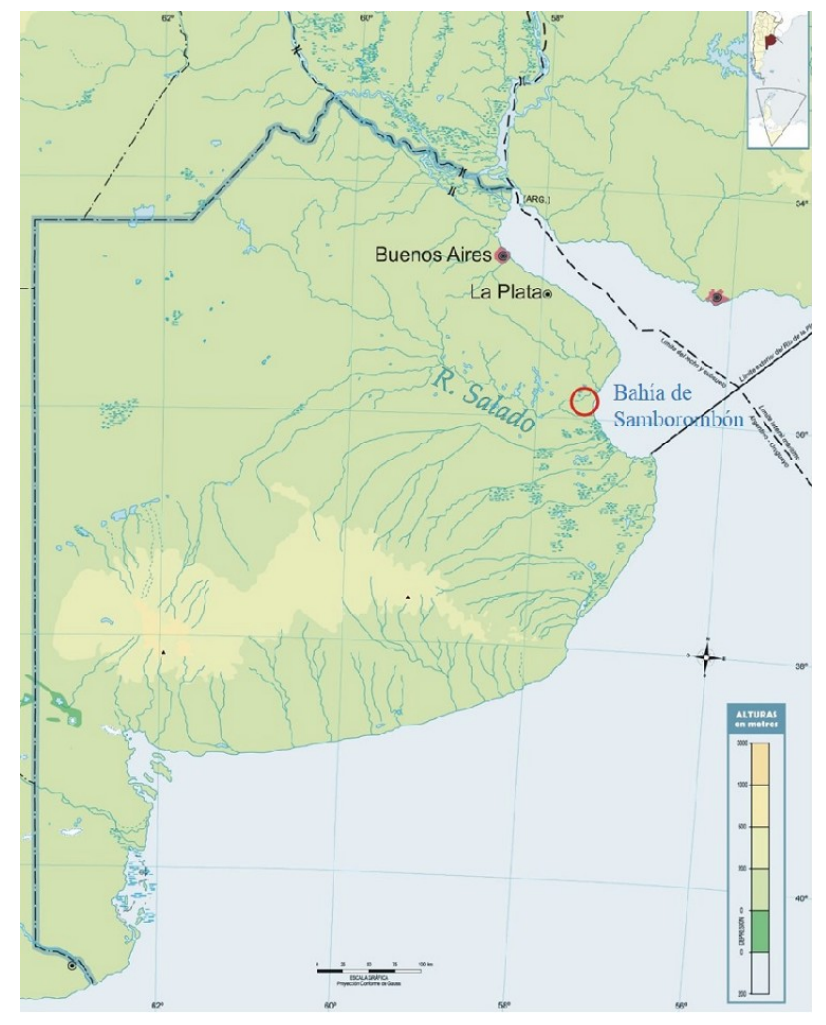

En la Figura 2 se reproduce un mapa elaborado por el padre Cardiel en 1749, donde figura el segundo asentamiento de la reducción Nuestra Señora de la Concepción (ver adelante), a la derecha de la cual se ilustra gráficamente la rinconada de forma aproximadamente triangular que quedaba comprendida entre ésta, el mar y el río Salado por el norte, indicado con las leyendas 3 y 4 que ese sector era la "Estancia” del "Pueblo de los Pampas".

Figura 2. Fragmento del mapa de Joseph Cardiel "Viaje de parte de la Tierra de Magallanes hecho año 1748 por tierra dentro y por la playa del mar” 


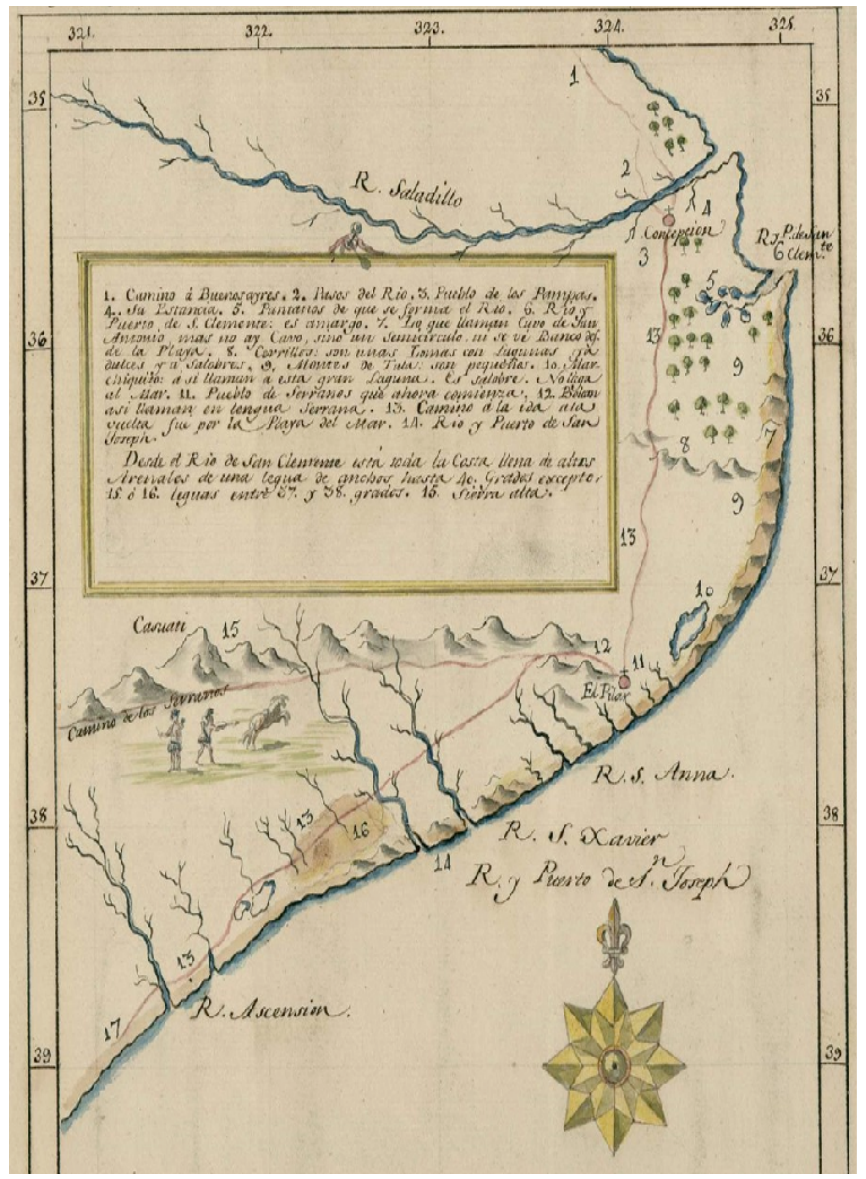

En líneas generales, las descripciones ambientales del paraje en el que se fundó inicialmente la reducción son coincidentes: recalcan la presencia de varias fuentes de agua potable, la buena disponibilidad de leña y la riqueza de los recursos faunísticos locales. Así, por ejemplo, el padre Lozano informaba en las Cartas Anuas correspondientes que

“El paraje de la nueva reducción (...) tiene diferentes fuentes de agua dulce, las que juntas forman un arroyo bastante grande, el que desemboca en el río Salado (...) En los alrededores se hallan pequeños bosques de arbustos y árboles; la tierra misma es fértil, y libre de la plaga de las hormigas (...) Los vastos campos abundan en avestruces, puercos silvestres y otros animales de caza; pero ante todo de un sinnúmero de yeguas silvestres” (Leonhardt, 1924b, p. 372-373).

Encontramos más referencias sobre las especies animales autóctonas en la correspondencia que escribió el padre Strobel durante los meses inmediatamente posteriores a la fundación del pueblo, desde donde este misionero describió, el 3 de octubre de 1740, que la "región es abundante en puercos silvestres, perros bravos, perdices, avestruces, y ante todo caballos cimarrones, cuya carne es el alimento de los Pampas” (Leonhardt, 1924c, p. 442).

Sánchez Labrador, por su parte, resaltaba el potencial de recursos ictícolas que posibilitaba la cercanía al río Salado, el cual era "abundantísimo de pescado”, junto a la disponibilidad de agua dada por "un arroyo, y unas fuentes, o manantiales de aguas potables, y dulces, que salen de los arenales, en las orillas, y riberas del río de la Plata” y la posibilidad de obtener leña en "algunos 
bosquecillos, cuya madera aunque muy vil, pero que podía servir de leña para el fuego, y algún otro uso” (Sánchez Labrador [1772], 1936, p. 84-85). Debe destacarse que la madera provista por los montes de tala o "islas”-según entonces se los denominaba- en esa zona, también era aprovechada por los vecinos españoles, quienes presentaron prontamente sus quejas por haber perdido

“la libertad que tenían antes para cortar leña en el paraje donde está la Reducción, con buenas islas pobladas de árboles que se abastecía esta ciudad con leña, y carbón los estancieros criadores de ganados; cortaban palos para corrales, ranchos y galpones, para su habitación” (AGI, Charcas 221, opinión de Carlos Nobares durante el Acuerdo del Cabildo del 4-10-1744).

En cuanto a la composición demográfica, la información documental analizada permite afirmar que la población inicial de la reducción estaba formada por cinco agrupaciones lideradas por cuatro caciques “pampas carayet”: Lorenzo Manchado, José Acazuzo, Lorenzo Massiel, Pedro Millán y el cacique “pampa serrano”: José Yahatí (Hux, 1993, p. 30; Leonhardt, 1924b, p. 373). Según surge de la certificación que hicieron los padres Manuel Querini y Matías Strobel el 20 de noviembre de 1742, eran "todos los indios Pampas y Serranos, que vivían esparcidos por las estancias de Buenos Aires” (Furlong, 1938; Leonhardt, 1924c, p. 441-449), muchos de los cuales habían sido previamente bautizados allí.

El caso de José Yahatí reviste particular interés ya que poco tiempo después se fue del pueblo, en buenos términos con los padres a punto tal que les había prometido hacer gestiones para frenar las hostilidades indígenas hacia las misiones bonaerenses, según el padre Leonhardt (1924b, p. 375). Unos años más tarde, este cacique se incorporó a la misión de Nuestra Señora del Pilar del Volcán, donde vivió con sus toldos entre 1749 y 1750 (Sánchez Labrador, [1772] 1936, p. 102-103).

Si bien los indígenas reducidos eran "350 almas, todo el resto de la tribu”, acorde lo afirmara el padre M. Strobel el 3 de octubre de 1740 en una de sus cartas (Leonhardt, 1924c, p. 442), los misioneros no perdían la esperanza de aumentar esa cifra "por la llegada de otros Pampas vagantes por los montes, y (...) de otras clases de indios, tan pronto como hubieran visto con qué comodidad se vivía» (Leonhardt, 1924b, p. 373). No obstante, también quedó registrada la existencia de conflictos interpersonales en el núcleo inicial de población originaria de la reducción, ya que los misioneros señalaban que había "según sus parcialidades, muchas enemistades y odios que cuando están bebidos prorrumpen en pendencias y muertes, como sucedió [en 1744] (...) que por esta causa quedaron tres muertos de la una parcialidad y casi todos heridos de la otra” (AGI, Charcas 384, carta del Padre Provincial B. Nusdorffer, al rey del 30-8-1745) . Completaban los habitantes del pueblo: 1) un contingente de indígenas guaraníes procedentes de las misiones del Paraguay, que acompañaba a los padres como auxiliares y maestros artesanos y 2) una escolta de soldados que había sido enviada por el gobernador Miguel de Salcedo.

La certificación realizada por los padres M. Querini y M. Strobel a los efectos de recibir el sínodo anual permite tener una semblanza de las características arquitectónicas del primer asentamiento a dos años de su fundación, el cual resulta de fundamental importancia para su localización actual. Según la traducción y la transcripción de dicha certificación hecha por el padre Leonhardt, hacia 1742 la reducción constaba de 26 casas o ranchos, para vivienda de los indígenas reducidos, y dos 
casas para los padres que fueron construidas de madera y adobe, como quedó referido en la carta escrita por Strobel del 3 de octubre de 1740 (Leonhardt, 1924c, p. 442). Una capilla que había sido edificada con los mismos materiales "aunque pobre y cubierta de paja conforme a su corto caudal, pero capaz de recibir toda la gente del pueblo"; en la citada fuente se aclara que hasta la finalización de las obras de construcción de la capilla, un toldo cumplía su función. Esta situación fue certificada luego por Querini y Strobel el 20 de noviembre de 1742 (reproducida en Furlong, 1938 y Leonhardt, 1924c, p. 441-449).

Sin embargo, debe notarse que, respecto del tipo constructivo de las viviendas, la traducción al español de la misma carta que casi quince años después hiciera el padre Furlong es distinta a la que había publicado inicialmente Leonhardt. El primero consigna que los padres habían "hecho dos casitas con troncos y barro; y en parte con ladrillos que fabricamos” (Furlong, 1938, p. 96-98). La diferencia entre ambas revela un dato material no menor, que puede sugerir la cocción de los ladrillos de adobe in situ, es decir, en la misma reducción, tal como sabemos que se hizo posteriormente una vez que el pueblo debió ser trasladado. El empleo de ladrillos de adobe cocido, a diferencia del adobe común cuyas características determinan un proceso de desintegración veloz por acción de las inclemencias climáticas, constituye un indicio de buena visibilidad arqueológica que es central para definir las estrategias de búsqueda en el terreno de los restos edilicios, que deben tener en cuenta el tipo de materiales constructivos así como las técnicas arquitectónicas empleadas.

Si bien no se cuenta con ningún plano que contenga el trazado de Nuestra Señora de la Concepción de los Indios Pampas, entre los estudios consultados hay consenso en suponer que tuvo la misma disposición urbanística regular que la mayor parte de las reducciones jesuíticas. Las mismas estaban organizadas en torno a una plaza central, frente a uno de cuyos lados se erigía la Iglesia, adyacentes a ésta se ubicaban la residencia de los padres y el cementerio, mientras que las casas de los catecúmenos ocupaban los restantes lados de la plaza (Cardiel, [1771] 1994; Furlong, 1938; Maeder, 1999; Moncaut, 1981). Sirve de apoyo adicional a esta hipótesis el siguiente relato contenido en las Cartas Anuas acerca de las actividades llevadas a cabo durante la fundación del pueblo:

“Contentos estaban los Indios Pampas con la amenidad del lugar y luego pusieron mano a la construcción de sus habitaciones (...) Dispusieron sus toldos en forma de calles y con plaza en el medio, donde se erigió la señal de la santa cruz” (Leonhardt, 1924b, p. 373).

Esos primeros años los padres decidieron que el lugar debía fortificarse ya que estaba "expuesto a las correrías de los indios Serranos y Aucaes”, como fue notado por Querini y Strobel en la certificación ya citada que ambos hicieron el 20 de noviembre de 1742 (Furlong, 1938). En consecuencia, el pueblo fue rodeado por una empalizada y una fosa defensiva de dos varas de ancho y de profundidad, mientras que el gobernador dispuso el envío de dos cañones y algunas lanzas para su resguardo (carta de M. Strobel del 3-10-1740, reproducida en Leonhardt, 1924c, p. 441-449).

Hacia fines de 1742, el panorama que ofrecía la reducción De la Concepción para las autoridades coloniales era muy promisorio, según surge de la carta enviada por el propio rey de España al gobernador Salcedo con motivo de haber aprobado la asignación de 400 pesos estipulados para los 
misioneros. En efecto, el monarca reconocía que la fundación de la reducción había tenido

"tan buen efecto a Ntra. Santa Fe, que ya pasan de doscientos cristianos, y muchos casados, con buena esperanza de que todos (...) abracen de veras la fe Catolica, y no menor de que habiendo en ese Pueblo algunos Indios Serranos, y de otras naciones de las muchas, que habitan en esa parte del Sur, y en las dilatadas Campañas, y Sierras que (...) corren hasta el Estrecho de Magallanes, sean estos instrumentos para facilitar la Predicación del Santo Evangelio, y conversion de esas naciones, (...) que resultara, a mas del importante fin de la Religion, el provecho de que poblada esa costa, con las Reducciones que se fueren haciendo, se evitara el inconveniente de cualquiera desembarco, o Poblacion que pudieren intentar los enemigos” (AGN, legajo 183, Doc.1160, carta del rey al gobernador Salcedo del 25-10-1742).

Nuevamente se evidencia en el documento anterior el doble objetivo, religioso y geopolítico, que tuvo desde sus inicios la empresa misional en la región pampeana.

\section{El traslado del primer pueblo}

El padre Matías Strobel advirtió temprano el principal inconveniente que presentaba el lugar donde se había instalado el nuevo pueblo de indígenas pampas y serranos y que fue ulteriormente el motivo del traslado del mismo. En correspondencia escrita en 1740, a pocos meses de la fundación, este misionero notó que se trataba de "una tierra amplísima, que fácilmente se inunda cuando sobrevienen grandes lluvias, y (...) por esta razón muy húmeda” (carta del 3-10-1740, transcripta en Leonhardt, 1924c, p. 442). Las dificultades concretas se evidenciaron al poco tiempo, ya que "un año de muchas lluvias (...) Inundose toda aquella tierra, quedando laguna sin utilidad para labrar las sementeras” (Sánchez Labrador [1772] 1936, p. 88). Además de los perjuicios derivados de no poder cultivar, estas inundaciones promovieron una serie de enfermedades que fueron atribuidas a condiciones insalubres causadas por el exceso de humedad, principalmente en verano (Moncaut, 1981, p. 65).

Si bien no hemos hallado datos precisos sobre la fecha exacta del abandono del primer asentamiento, el padre Furlong (1938) estima que éste se habría producido entre 1743 y 1744, mientras que el estudioso platense Carlos Moncaut (1981) señala que para marzo de 1745 ya se había trasladado el pueblo a su segundo emplazamiento. Esta última fecha es más cercana a la estimación que surge de la crónica antes citada del jesuita Sánchez Labrador ([1772] 1936, p. 88), quien menciona un pedido de escolta de soldados que fue efectuado al gobernador en 1745, cuando los padres ya estaban en el nuevo pueblo. Adicionalmente, Moncaut cita una carta del Obispo de Paraguay al Rey del 6 de marzo de 1745, en la que el primero se refiere al "pueblo nuevamente fundado de la Concepción de los Pampas” (1981, p. 72). Debe tenerse en cuenta, por otra parte, que las Cartas Anuas que escribió Lozano comprenden hasta 1743 y que hasta ese momento no se menciona ningún traslado de la reducción De la Concepción.

Lo cierto es que hacia 1744-1745 ya se había producido la mudanza del emplazamiento inicial hacia "una colina, que estaba en distancia de dos leguas, y se llamaba Loma de los Negros (...) Estaba rodeada de bosque” (Sánchez Labrador, [1772] 1936, p. 88). Esta información es coincidente con la descripción que hizo el padre P. Charlevoix y fue transcripta por Moncaut (1981, p. 65). La 
“Numeración Anual del Pueblo de Nuestra Señora de los Indios Pampas” de 1746 (transcripta en Leonhardt, 1924c, p. 446), redactada desde el nuevo pueblo, muestra la celeridad con que se estaba construyendo el mismo, que para entonces ya contaba con "más de 30 ranchos”, de adobe y paja, presumiblemente, a la vez que se estaba trabajando «en el material necesario para acabar la iglesia”, habiéndose comenzado "a formar la plaza del pueblo en buena forma. Se han hecho tres casas continuadas de adobe”. Como se adelantó, la residencia de los padres y la iglesia aquí fueron edificadas con ladrillos cocidos y maderas que habían sido trasladadas desde Buenos Aires, siendo el cuidado y reparación de esta última motivo de diversas comunicaciones y recomendaciones posteriores (AGN, Sala IX, Legajo 6-10-1, carta del padre M. García del 30-12-1747 y carta del padre M. Strobel del 14-1-1748).

Durante esos años, la población de la reducción fue bastante fluctuante, tanto en lo que respecta a los catecúmenos como a los indígenas que sólo la visitaban por temporadas. Los primeros, lejos de haberse establecido en el pueblo, continuaban yendo periódicamente a las estancias y a los campos vecinos, situación que quedó reflejada en el informe que hicieron los padres en 1744, cuando señalaron que

"el exceso en el número de las almas, que se halla este año algo mayor que el año pasado, proviene de los nuestros fugitivos, que fueron echados (...) de las estancias de Buenos Aires y varios de ellos se volvieron a éste su pueblo” (AGN, legajo 289, Numeración Anual del Pueblo de la Concepción de los Indios Pampas, 1744).

En cuanto a los segundos, son numerosas las referencias a las estadías breves de "serranos", como en 1745, cuando los jesuitas referían que "el aumento del Pueblo (...) se debe a haberse agregado algunos Indios pampas y Serranos con su Cacique. Por todos 57 almas. Entre estos hay 10 familias de infieles (...) y dos de indios ya cristianos” (AGN, legajo 189, Numeración Anual del Pueblo de la Concepción de los Indios Pampas, 1745). También quedó registrada la presencia del cacique serrano Yepelye, quien en 1746 se detuvo "mucho tiempo en estos campos corriendo yeguas, con pretexto de buscar agua para su retirada", acompañado por "algunos indios ladinos que se han criado en estas estancias” (AGN, Sala IX, carta del padre M. Strobel al gobernador de Buenos Aires del 2612-1746).

En ocasión de una visita a la reducción, el entones Padre Provincial Manuel Querini redactó un memorial fechado el 29 de diciembre de 1748, por medio del cual sugirió una serie de medidas defensivas que evidencian el aumento del clima de hostilidad interétnica que se experimentaba para ese momento. Así, este religioso advirtió la necesidad de reforzar el armamento con que los misioneros debían protegerse:

“Para que los Padres puedan vivir con más quietud, y seguridad, acabado el Recitorio y Cocina se cerrará nuestro patio con pared de ladrillo y en una esquina del mismo patio se levantará un Baluarte para poner en él las cuatro piezas de artillería” (Memorial del padre Querini del 29-12-1748, parcialmente transcripto en Furlong, 1938, p. 112).

En lo que respecta a la producción agropecuaria, las distintas fuentes estudiadas son concordantes acerca que los jesuitas buscaron incesantemente, aunque con resultados dispares, que cada uno de 
los ranchos en los que habitaban los indígenas tuviera sus correspondientes sementeras. La última información arquitectónica que hemos podido recabar refiere justamente a la construcción de una tahona, que fue concluida para comienzos de 1749 (AGN, Sala IX, legajo 6-10-1, carta del padre M. Strobel del 18-4-1749 y carta del padre Procurador del 6-11-1749).

Como era usual en todas las reducciones, se plantaron distintos árboles frutales para el consumo comunal, de los que tenemos testimonio gracias a la "Numeración Anual del Pueblo de Nuestra Señora de los Indios Pampas” de 1746 (transcripta en Leonhardt, 1924c, p. 446) y al "Memorial del Padre M. Querini del 29 de diciembre de 1748” (transcripto en Furlong, 1938, p. 112), ya mencionados. Según concluye el padre Furlong "la estancia de la reducción abarcaba toda la zona noroeste y sudoeste de la misma, a lo largo del Salado y en dirección a las antiguas estaciones de Guerrero y Castelli, y aún al norte del Salado hacia las lagunas de Chascomús” (en Moncaut, 1981, p. 78), tierras donde pastaban más de 4000 cabezas vacunas, además de ganado yeguarizo, mular y algunos bueyes.

La semblanza anterior acerca del ámbito en el que se fundó la reducción Ntra. Sra. de la Concepción, su estructura urbanística y las características arquitectónicas de sus edificaciones, que se elaboró a partir del corpus documental y bibliográfico analizado, abre una serie de interrogantes sobre los cuales esperamos avanzar mediante las pesquisas arqueológicas. Al respecto, nos planteamos si los saberes y prácticas espaciales indígenas -tanto de los grupos locales como de los guaraníes- incidieron en la elección del paraje, en la configuración inicial de la reducción así como en el devenir del poblado durante los años que estuvo en funcionamiento, mudanza incluida. En las fuentes documentales y la bibliografía jesuita consultada no se mencionan elementos que lo hagan suponer, más bien se trasluce que la reducción se construyó siguiendo una planificación previa de los padres, estando bajo su órbita exclusiva la dirección y ejecución de los trabajos (por ejemplo, en las crónicas de Sánchez Labrador, Leonhartd y Furlong). No obstante, el estudio arqueológico de ambos asentamientos permitirá poner en cuestión esta hipótesis, por medio del cotejo del modelo clásico de reducción jesuita, por un lado, y de las implicancias derivadas de los testimonios de los misioneros, por el otro, con la materialidad concreta de ambos poblados que subsista hasta hoy.

\section{Tras las huellas de la reducción de los indios pampas}

Los dos pueblos que conformaron consecutivamente la reducción jesuítica Nuestra Señora de la Purísima Concepción de los Indios Pampas estaban localizados en las tierras que dos décadas después reclamó para sí Clemente López Osornio. Este último efectuó la presentación correspondiente en 1775 alegando que era poseedor de dichos terrenos desde 1761, o sea, ocho años después del abandono definitivo del segundo asentamiento de la reducción que se había producido en febrero de 1753. Luego de una larga tramitación judicial, las tierras le fueron concedidas finalmente al yerno de Clemente López Osornio, León Ortíz de Rosas, en 1811, pasando a formar parte de la estancia Rincón de López, ubicada en el actual partido bonaerense de Castelli. Dicha estancia subsiste actualmente, pero no mantiene su extensión original ya que atravesó una secuencia de subdivisiones, fraccionamientos y ventas desde entonces hasta nuestros días.

En el marco del proyecto de investigación arqueológica iniciado en 1999 se localizó en el terreno el sitio en el cual se encuentran las ruinas del segundo asentamiento de la reducción Ntra. Sra. de la 
Concepción de los Indios Pampas (Pedrotta, 2011; 2013), pero continua siendo una incógnita la cuestión del lugar preciso en el que se instalara el primer pueblo que había sido fundado en mayo de 1740. Las fuentes cartográficas que contienen información al respecto son pocas y ambiguas. Únicamente disponemos de dos mapas en los que aparece la ubicación conjunta de ambos asentamientos, un elemento muy relevante ya que permite estimar la ubicación relativa del primero de ellos con relación al emplazamiento conocido del segundo.

El primer mapa fue confeccionado por el padre Cardiel luego de la expedición que hizo "hacia las nacientes del río del Sauce” en 1748, derrotero que lo condujo hasta la desembocadura del actual arroyo Claromecó en la costa sudeste de la provincia de Buenos Aires (Martínez Sierra, 1975; Outes, 1930). Un fragmento de dicho mapa se reproduce en la Figura 3, en el cual se denomina "Pueblo Viejo" al primer emplazamiento que localiza sobre la margen derecha de un arroyo que llama "río Dulce" y figura como el último tributario de la margen sur del río Salado antes de su desembocadura. Nótese también que en este mapa aparece identificado claramente el "Rincón de la Estancia” que tenía la reducción, cuyas características fueron analizadas en las secciones precedentes.

Figura 3. Detalle del mapa confeccionado por el P. Cardiel en 1748 donde figura la ubicación de los dos emplazamientos de la Reducción

De la Concepción (reproducido en Outes, 1930).

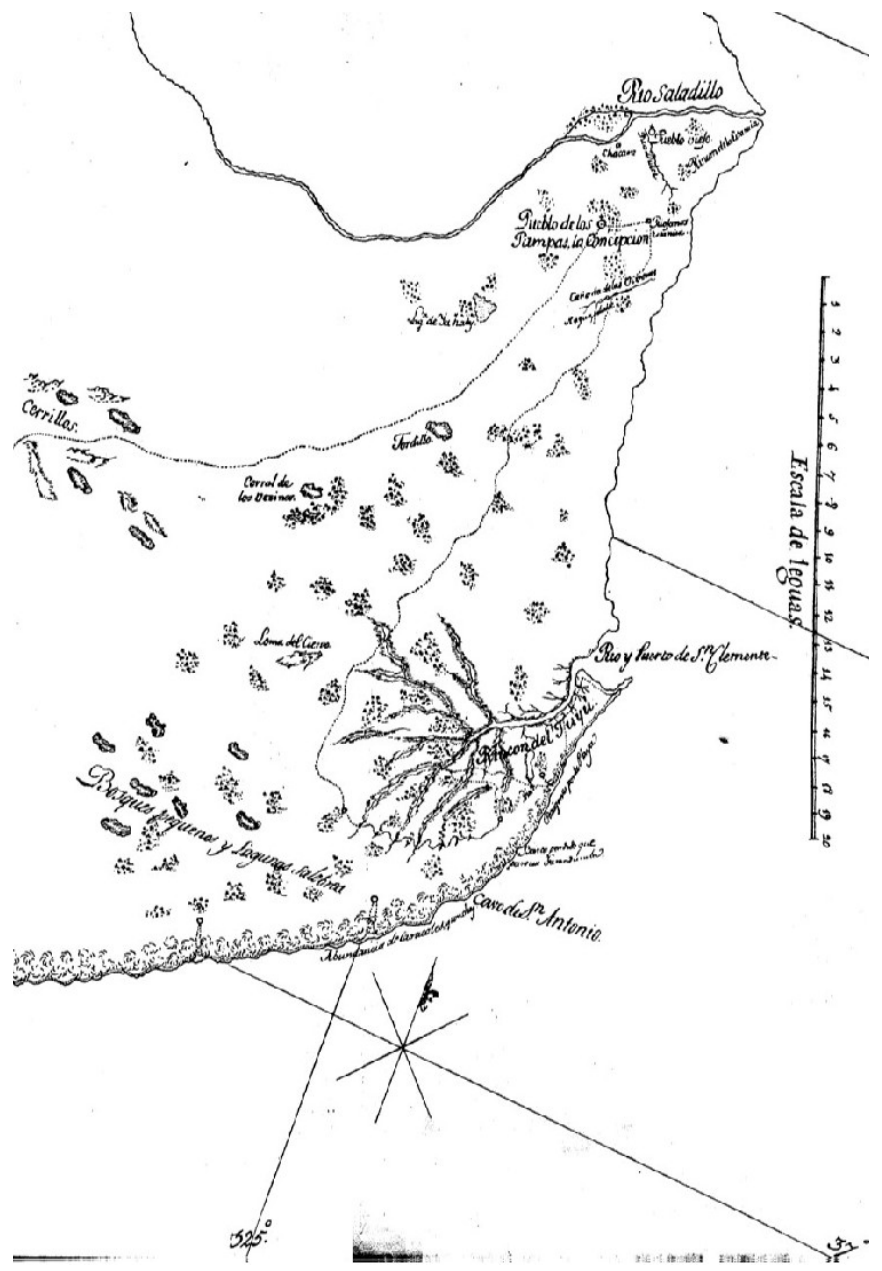


El segundo mapa, que ha sido atribuido al padre T. Falkner y se reproduce en la Figura 4, habría sido confeccionado alrededor de 1780 (Furlong, 1936). Dadas las notables distorsiones en la representación de la región pampeana, las inexactitudes que presenta el trazado de la Bahía de Samborombón y la magnitud de la escala utilizada en esa carta, su aporte se limita a la mención a una misión abandonada que aparece con la leyenda "Miss.n extinct” y que correspondería al primer pueblo, así como la representación de un lugar denominado "la Conception de los Pampas. Miss.n established in 1740", que por su ubicación relativa hacia el sur del primero interpretamos como el segundo asentamiento.

\section{Figura 4. Mapa atribuido al P. T. Falkner (ca. 1780), donde están ubicados los dos emplazamientos que formaron la reducción De la Concepción (Furlong, 1936).}

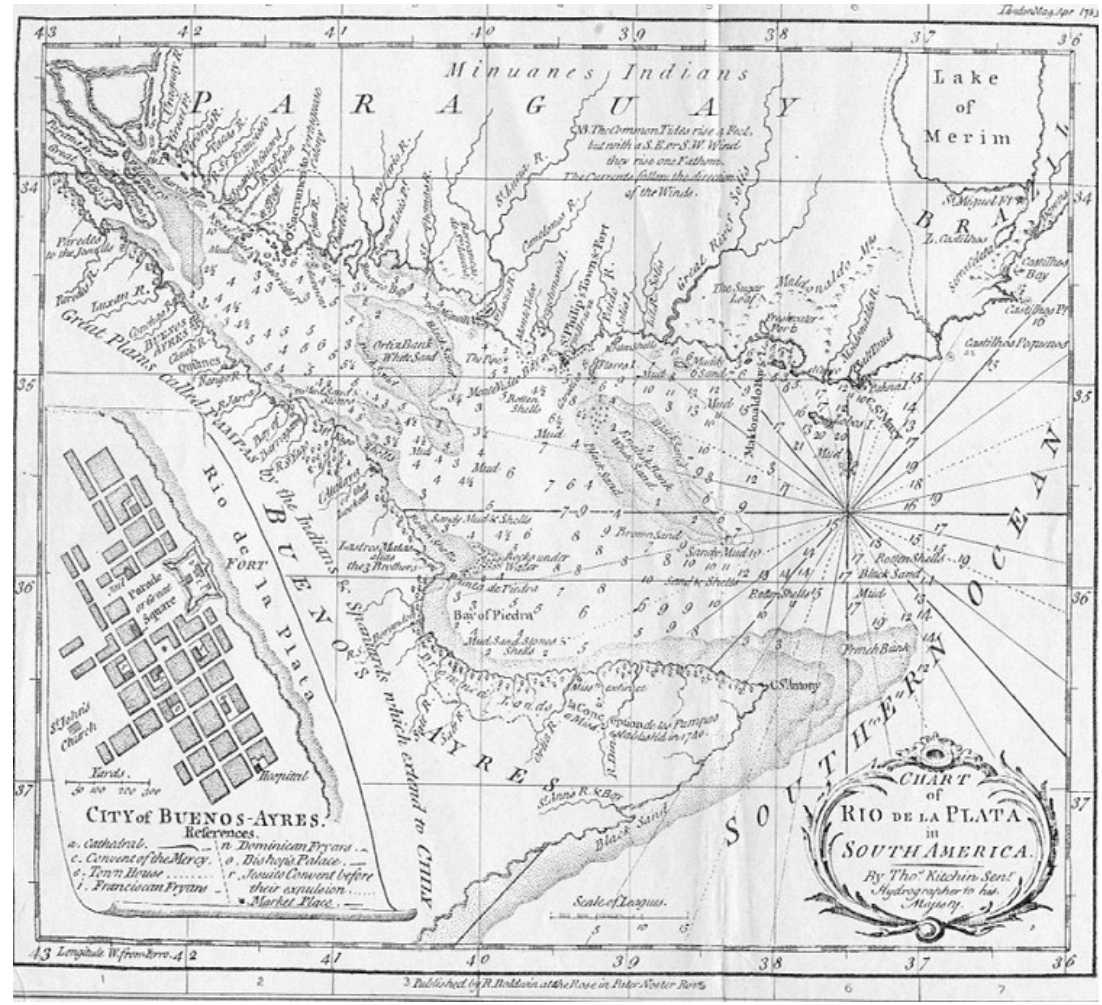

Los únicos investigadores que han analizado con cierto detenimiento esta cuestión son Furlong (1967), Outes (1930) y Moncaut (1981). Los dos últimos coinciden en identificar al nombrado "río Dulce” por el padre Cardiel con el actual “arroyo De la Estancia”. Este arroyo aparece representado por primera vez bajo esa denominación en el croquis que efectuó el piloto Pedro Juan de Alberdi en 1778 al realizar la mensura de esas tierras, con motivo de la ya mencionada presentación que efectuó Clemente López Osornio. En el mismo croquis de Alberdi surge que entonces existía una “población” sobre la margen izquierda del “arroyo de la Estancia” -que posiblemente se trate del casco originario del Rincón de López- que no figura en la siguiente medición del campo que fue llevada a cabo por el agrimensor Marcos Chiclana en 1825 ni en las mensuras posteriores, cuyo 
análisis crítico fue efectuado por Outes (1930). Cabe aclarar que en la actualidad la casa principal y las demás edificaciones de la estancia Rincón de López se ubican justamente sobre la margen izquierda del arroyo De la Estancia, muy próximos a la confluencia entre éste y el río Salado, con el cual limitan por el norte.

En resumen, sobre la base del análisis e interpretación del mapa de Cardiel y de las fuentes documentales inéditas ya mencionadas, Outes (1930) considera que el primer asentamiento se ubica hacia el noreste del segundo, cerca del actual casco de la estancia Rincón de López y de la antigua población de la misma, estando separada de esta última por el actual arroyo De la Estancia. Furlong (1967), por su parte, concluye que el primer pueblo estuvo localizado en una pequeña loma sobre la margen derecha del actual arroyo Dulce, tributario sur del río Salado, cuyo topónimo se habría conservado, aunque se encuentra bastante alejado de la desembocadura de dicho río en la bahía de Samborombón. En tercer lugar, Moncaut (1981), sostiene que el asentamiento fundacional se situaba en la margen derecha del arroyo Dulce -aunque no especifica si éste correspondería al arroyo homónimo actual o al arroyo De la Estancia- a cuatro leguas de la bahía de Samborombón y a menos de una legua al sur del río Salado.

Teniendo en cuenta las conclusiones a las que arribaron los autores antes citados, así como los resultados parciales de nuestras propias pesquisas sobre fuentes documentales y cartográficas, inéditas y publicadas, se está llevando a cabo un programa de investigaciones arqueológicas en el marco del cual se desarrollaron trabajos de prospección y detección por sensores remotos en aquellos lugares considerados como posibles localizaciones de este primer poblado. Hasta el momento se hicieron trabajos de campo en tres sectores (S, E y T) de la actual estancia Rincón de López, con el invalorable apoyo del Museo y Archivo Regional de Castelli.

El Sector S corresponde a la margen sur de un meandro formado por el río Salado, que es denominado por los pobladores locales "Cementerio de los Indios"; allí se excavaron tres sondeos exploratorios de $0,50 \mathrm{~m}$ por $0,50 \mathrm{~m}$, espaciados cada 25 metros a lo largo de un eje que atraviesa en forma longitudinal dicho meandro, sin hallar materiales culturales. El Sector E es una barranca sobre la margen sur del Río Salado, donde la erosión eólica y fluvial había dejado expuestos huesos de mamíferos grandes (bóvidos y equinos, principalmente) que se disponían a modo de capa estratigráfica observable entre los 0,15-0,20 m y 0,60 m de profundidad y a lo largo de unos 14 metros. Aquí se planteó una pequeña excavación de $2 \mathrm{~m}$ de largo por $1 \mathrm{~m}$ de ancho, distante dos metros de la barranca, a fin de constatar si dichos huesos presentaban alguna asociación con otro tipo de restos materiales para contextualizarlos cronológica y funcionalmente. Dicha excavación dejó al descubierto la capa continua de restos óseos, que resultaron hallarse totalmente articulados y en muy bien estado de conservación, pero sin presentar ningún material cultural.

El Sector T comprende un área localizada sobre la margen derecha del actual arroyo De la Estancia, donde se realizaron las tareas de campo más intensivas, habiéndose efectuado el relevamiento magnético inicial de una amplia superficie de terreno de más de $700 \mathrm{~m}$ de largo por un ancho que varía entre los 200 y $400 \mathrm{~m}$. El mismo fue subdividido en los subsectores, I, II y III, dentro de cada uno de los cuales se planteó una grilla de transectas paralelas espaciadas 25 metros entre sí: 13 transectas en el subsector I, 10 en el II y 9 en el III. Una vez planteadas las transectas, se hicieron mediciones magnéticas a intervalos regulares siguiendo la misma dirección. 
Los valores obtenidos fueron cotejados con las mediciones de un segundo magnetómetro que fue instalado en un lugar apartado a fin de registrar la variación diaria a intervalos de un minuto. El procesamiento de los datos obtenidos, tanto por el magnetómetro fijo como por el móvil, fue realizado por los geofísicos J. Gianibelli y R. Cabassi, ambos del Departamento de Geomagnetismo de la Facultad de Ciencias Astronómicas y Geofísicas de la Universidad Nacional de La Plata. Ambos elaboraron los mapas magnéticos de los subsectores I, II y III.

Estos mapas sirven de base para planificar las siguientes etapas del trabajo de campo, apuntando hacia aquellos lugares donde la presencia de anomalías magnéticas pueda ser un indicador de la existencia de fragmentos, objetos y/o restos arquitectónicos enterrados. Una de las principales dificultades que reportó este método de detección obedece a la cercanía de las edificaciones e instalaciones actuales de la estancia, cuyas emisiones introdujeron fuertes distorsiones en los mapas de anomalías magnéticas. Hasta la fecha, se excavaron tres cuadrículas exploratorias de $1 \mathrm{~m}$ por $1 \mathrm{~m}$ en el Subsector II, situado en la margen sur de un antiguo meandro del río Salado, sin hallar restos arqueológicos que puedan corresponder a la reducción jesuita (Pedrotta, 2000, 2013).

En contraposición a la aún incierta situación del primer asentamiento, el segundo establecimiento de la reducción Nuestra Señora de la Concepción sí está localizado, constatándose que sus restos arquitectónicos se encuentran dentro del perímetro de un predio de propiedad privada, donde actualmente se desarrollan actividades agropecuarias y caza deportiva. Este sitio se encuentra en una loma de forma ovalada, cuyo eje longitudinal mide unos $3 \mathrm{~km}$, que es muy visible en las fotografías aéreas de la zona del Ministerio de Obras y Servicios Públicos de la Provincia de Buenos Aires (C 1189-50). Se trata de una loma relativamente alta, una “colina”, como bien la describiera Sánchez Labrador, ya que alcanza los $18 \mathrm{msnm}$ en un entorno de llanuras bajas cuya altitud máxima oscila entre los 5 y $10 \mathrm{msnm}$, como consta en la carta topográfica del Instituto Geográfico Militar (2557-32-4).

Las fuentes cartográficas antes citadas, así como cartas y mensuras posteriores, registran los elocuentes topónimos “loma de la Reducción”, “Puesto de la Reducción” y “Loma la Reducción”, haciendo numerosas referencias, además, a la presencia de abundantes "islas” de tala en dicha loma. La toponimia regional antes mencionada, así como la coincidente ubicación relativa de la misma en la cartografía que fueron produciendo las sucesivas mensuras de esas tierras desde el último tercio del siglo XVIII y en distintas cartas geográficas generales de la provincia de Buenos Aires que fueron confeccionadas en las primeras décadas del siglo XIX, refuerzan esta aseveración (Outes, 1930).

La visita a este lugar que efectuó Carlos Moncaut en 1955 testifica, además, la presencia de restos arquitectónicos enterrados. De las indagaciones que había realizado previamente el padre Furlong (1938), surge que viejos vecinos de la zona habían visto en pie una parte de pared que rodeaba el cementerio. Además, valiosos elementos arquitectónicos procedentes de allí, tales como ladrillos, baldosas, tejas y otros elementos constructivos, están conservados y resguardados en el Museo y Archivo Regional de Castelli, afortunadamente. Las ruinas del segundo asentamiento de la reducción constituyen el único testimonio arqueológico conocido actualmente acerca de la actividad misional y la empresa evangelizadora que llevaron a cabo los jesuitas en la región pampeana durante el siglo XVIII; sin embargo, son objeto de depredación y se hallan en el descuido más 
absoluto.

Finalmente, debe constar que hace quince años solicitamos la intervención del Centro de Registro del Patrimonio Arqueológico y Paleontológico de la Provincia de Buenos Aires debido a los impedimentos puestos por los propietarios del predio para el desarrollo de las investigaciones arqueológicas y ante las crecientes evidencias de la destrucción de restos arquitectónicos y el saqueo de piezas arqueológicas por "buscadores de tesoros". Luego de seis años sin resultado alguno en el ámbito provincial, requerimos la intervención de la autoridad nacional en materia de patrimonio arqueológico; así en 2007 se hizo una extensa presentación del caso ante el Instituto Nacional de Antropología y Pensamiento Latinoamericano, organismo a cargo de "Ejercer la tutela del Patrimonio Arqueológico" como parte del patrimonio cultural de la Nación Argentina. No obstante la sucesión de presentaciones y reclamos que hemos hecho en los últimos quince años tanto a las autoridades provinciales como a las nacionales ya que la protección del patrimonio arqueológico es un deber concurrente para ambas. Hasta la fecha no se ha emprendido ni una sola acción para cuidar y preservar los restos arqueológicos de la reducción Nuestra Señora de la Concepción de los Indios Pampas (tema tratado en detalle en Pedrotta, 2011, 2013).

\section{Conclusiones}

En las secciones precedentes hemos presentado un análisis pormenorizado acerca del entorno geográfico y las particularidades ambientales de los lugares donde se fundaron sucesivamente los dos asentamientos que conformaron la reducción Nuestra Señora de la Purísima Concepción de los Indios Pampas, así como se describieron las características de su núcleo de población inicial y se efectuó una primera aproximación a las características arquitectónicas y la disposición espacial de sus edificaciones. Para ello se han integrado los datos recabados en diversas fuentes documentales y cartográficas, inéditas y publicadas, junto a estudios previos que fueron llevados a cabo por otros investigadores.

Las fuentes consultadas coindicen en torno a que el paraje elegido para fundar la reducción formaba una suerte de rinconada natural, por sus características topográficas, además de contar con una buena provisión de agua dulce, pasturas y leña, así como recursos faunísticos diversos y abundantes que eran utilizados por las poblaciones indígenas locales, las cuales tenían una especial predilección por los caballos baguales. Al igual que las misiones fundadas posteriormente en el sector oriental del sistema de Tandilia -Nuestra Señora del Pilar del Volcán y Nuestra Señora de los Desamparados- la elección de este emplazamiento, tal como señalan de Lasa y Luiz (2011, p. 20) “respondió a las óptimas condiciones para un poblamiento permanente y al conocimiento de su importancia dentro del espacio económico indígena, tratándose de un área clave para los intercambios en función de la localización de los recursos”.

Teniendo en consideración el conjunto de fuentes documentales citadas previamente, podemos afirmar que la reducción Nuestra Señora de la Concepción contó con una serie de elementos arquitectónicos que deberían tener correlatos arqueológicos de cierta magnitud. Nos referimos especialmente a las viviendas de la población (formada por indígenas pampeanos, guaraníes y variables contingentes hispano-criollos) que consistían en ranchos de barro, adobe, madera y paja. Según los registros consultados, entre 15 y 20 de estas viviendas fueron construidas en el primer 
asentamiento, mientras que en el segundo su número superó las treinta.

Es posible que en el emplazamiento original, la iglesia, la casa de los misioneros, el cementerio y otras instalaciones administrativas hayan sido edificados con estos mismos materiales, mientras que en el segundo pueblo contamos con registros certeros que indican la elaboración de ladrillos para erigirlos. Ambos pueblos fueron rodeados por fosas y empalizadas defensivas de cierta magnitud, pero la visibilidad arqueológica de este tipo de rasgos en el terreno actual, habiendo transcurrido más de doscientos cincuenta años, debería ser muy baja. En adición, las referencias indirectas permiten suponer la construcción de diversas instalaciones vinculadas con las actividades agropecuarias, cuyas posibilidades de detección arqueológica son aún menores en comparación con las edificaciones antes mencionadas.

Por último, hemos planteado y discutido algunas hipótesis en las que venimos trabajando acerca del primer emplazamiento, así como la localización actual del lugar donde debió ser trasladado el pueblo a los pocos años de su fundación, que sirvieron como base para la planificación de las actividades de prospección y de técnicas de detección por geomagnetismo en el terreno. El avance y la intensificación de los trabajos arqueológicos en la zona permitirán aportar líneas de indagación adicionales sobre estas cuestiones, en particular en lo referido al lugar preciso del primer asentamiento que aún permanece irresuelto. A modo de comentario final, esperamos que este artículo contribuya a visibilizar el caso de las reducciones jesuitas en las pampas argentinas, así como ayude a concientizar acerca de la necesidad de conocerlas y de preservar los restos materiales de inmenso valor patrimonial -histórico, arqueológico y arquitectónico- que aún subsisten en el partido bonaerense de Castelli.

\section{Agradecimientos}

Son numerosas las personas que participan en la investigación arqueológica de la reducción De la Concepción, entre las que quisiera agradecer especialmente a quienes participaron en la búsqueda inicial de su primer asentamiento, sin que ello signifique olvidarme de las restantes. La Prof. Graciela Zubillaga apoyó desde un comienzo el proyecto, haciendo posible la puesta en marcha del mismo desde el ámbito del Museo y Archivo Regional de Castelli, además participó en las tareas de campo conjuntamente con Silvia y Ulises, personal técnico del mismo. La dirección actual del Museo y Archivo Regional de Castelli, encabezada por la Prof. María del Carmen Bordazahar ha dado un apoyo permanente al proyecto de investigación arqueológica, que agradezco especialmente. La Sra. Juana Casares permitió amablemente efectuar los trabajos arqueológicos en su establecimiento, prestando amplia colaboración, así como su encargado, Sr. Emir Ogazón, quien hizo gratas nuestras estadías en el mismo. Los geofísicos Julio Gianibelli y Rosalía Cabassi ensayaron desinteresadamente la aplicación de métodos de prospección magnética en el lugar. Todos los trabajos de campo contaron con el apoyo logístico y económico de la Municipalidad de Castelli. Agradezco el apoyo institucional del CONICET, la ANPCyT, la Fundación Félix de Azara y la Universidad Maimónides, a través del Departamento de Ciencias Naturales y Antropológicas del CEBBAD. Finalmente, agradezco los acertados comentarios y sugerencias efectuados por los evaluadores de este artículo. 


\section{Notas}

1 Este trabajo se enmarca en los proyectos "Paisajes indígenas construidos en las sierras bonaerenses” (PIP 349/12) y “Arqueología e historia de la frontera sur de Buenos Aires durante la segunda mitad del siglo XIX: campos, ejidos y territorio indígena desde una mirada interdisciplinar” (PIP 11220150100304), ambos financiados por el CONICET. Una versión preliminar del mismo fue presentada como ponencia en el XV Congreso de Historia de los Pueblos de la Provincia de Buenos Aires, La Plata (Argentina), abril de 2015.

$\underline{2}$ Ver también: AGN, legajo 183, carta del rey al gobernador Salcedo del 25-10-1742 y AGI en ME, Doc. I.21, Carta del rey al Padre Provincial de las Misiones de los Indios Pampas y Serranos del 237-1744.

\section{Referencias bibliográficas}

Arias, F. (2006). Misioneros jesuitas y sociedades indígenas en las pampas durante el siglo XVIII (Tesis de Doctorado inédita), Universidad Nacional del Centro de la Provincia de Buenos Aires, Facultad de Humanidades, Tandil, Argentina.

Arias, F. (2011/2012). Fronteras interétnicas en el espacio de las pampas durante la primera mitad del siglo XVIII. El caso del linaje de los caciques Bravos y sus relaciones interregionales. Anuario de la Escuela de Historia, 24, pp. 121-147.

Bohn Martins, M. C. (2014). Jesuítas e índios nas "missões austrais”: uma experiencia na pampa argentina (século XVIII). Revista História e Cultura, 3(2), pp. 233-249.

Cardiel, J. P. [1748] (1930). Diario del Viaje y Misión al Río del Sauce por fines de Marzo de 1748. Publicaciones del Instituto de Investigaciones Geográficas de la Facultad de Filosofía y Letras (serie A). Buenos Aires: Imprenta Coni.

Cardiel, J. P. ([1747] 1940). Carta inédita de la extremidad austral de América construida por el P. Cardiel en 1747, con un estudio histórico-geográfico del P. G. Furlong. Publicaciones de la Facultad de Filosofía y Letras de la Universidad de Buenos Aires, Nro.1 (Serie B). Buenos Aires: Facultad de Filosofía y Letras, Universidad de Buenos Aires.

Cardiel, J. P. ([1747] 1956). Defficultades q suele haber en la conversion de los infieles, y medios $\mathrm{p}^{\mathrm{a}}$ vencerlas. En M. A. Vignati (Ed.). Viajeros, obras y documentos para el estudio del hombre americano, (Tomo I, pp. 51-172). Buenos Aires: Imprenta Coni.

Cardiel, J. P. ([1771] 1994). Breve Relación de las Misiones del Paraguay. Buenos Aires: Secretaría de Cultura de la Nación y Ediciones Theoria.

Coni, E. A. (1979). Historia de las Vaquerías del Río de la Plata. Buenos Aires: Platero.

Crivelli, E. A. (1994). Araucanos en las pampas. Todo es Historia, 323, pp. 8-32.

Crivelli, E. A. (1997). Indian settlement system and seasonality in the pampas during the equestrian stage. The colonial period. Quaternary of South America and Anctartic Peninsula, 10, pp. 279-309.

de Lasa, L. y Luiz, M. T. (2011). Representaciones del espacio patagónico. Una interpretación de la cartografía jesuítica de los siglos XVII y XVIII. Cuadernos de Historia, 35, pp. 7-33. 
Dobrizhoffer, M. P. ([ca.1767-1797] 1967). Historia de los Abipones. Resistencia: Facultad de Humanidades de la Universidad Nacional del Nordeste, vol. I.

Hux, M. P. (1993). Caciques Puelches, Pampas y Serranos. Buenos Aires: Marymar.

Irurtia, M. P. (2007). Intercambio, novedad y estrategias: las misiones jesuíticas del sur desde la perspectiva indígena. Avá, 11, pp. 135-167.

Irurtia, M. P. (2008). El cacicazgo en la región pampeana-nordpatagónica argentina a mediados del siglo XVIII. La actuación de los caciques en torno a la instalación de misiones jesuíticas. Anthropologica, año XXVI(26), pp. 199-227.

Falkner, T. P. [ca. 1774] (1974). Descripción de la Patagonia y de las partes contiguas de la América del Sur. Buenos Aires: Hachette.

Furlong, G. P. (1936). Cartografía jesuítica del Río de la Plata. Publicaciones del Instituto de Investigaciones Históricas (vol. LXXI). Buenos Aires: Imprenta Jacobo Peuser.

Furlong, G. P. (1938). Entre los Pampas de Buenos Aires. Buenos Aires: Talleres Gráficos San Pablo.

Furlong, G. P. (1967). Manuel Querini S. J. y sus "Informes al Rey" 1747-1750. Buenos Aires: Ediciones Theoria.

Hernández Asencio, R. (2003). Caciques, jesuitas y chamanes en la frontera sur de Buenos Aires (1740-1753). Anuario de Estudios Americanos, LX(1), pp. 77-108.

Iglesias, M. (2000). Misiones jesuíticas al sur del río Salado. Sociedad indígena bonaerense y política de fronteras en el siglo XVIII. En E. Cruz (Comp.). Iglesia, misiones y religiosidad colonial (vol. 1, pp. 167-172). Jujuy: Centro de Estudios Indígenas y Coloniales (CEIC).

Jones, K. (1999). Warfare, reorganization, and readaptation at the margins of Spanish rule: the southern margin (1573-1882). En C. Salomon \& S. Schwartz (Eds.). The Cambridge of the Native Peoples of the Americas (vol. III, parte 2, pp. 138-183). Cambridge: Cambridge University Press.

León Solís, L. (1987). Malocas araucanas en las fronteras de Chile, Cuyo y Buenos Aires. Anuario de Estudios Americanos, XLIV, pp. 281-324.

León Solís, L. (1989/1990). Comercio, trabajo y contacto fronterizo en Chile, Cuyo y Buenos Aires, 1750-1800. Runa, XIX, pp. 177-221.

Leonhardt, C. P. (1924a). La Misión de los Indios Pampas. Estudios, 26, pp. 296-300.

Leonhardt, C. P. (1924b). La Misión de los Indios Pampas. Estudios, 26, pp. 370-375.

Leonhardt, C. P. (1924c). La Misión de los Indios Pampas. Estudios, 26, pp. 441-449.

Maeder, E. (1999). La iglesia misional y la evangelización del mundo indígena. En Nueva Historia de la Nación Argentina (Tomo II, pp. 433-468). Buenos Aires: Planeta.

Marfany, R. (1940). La frontera con los indios en el sur y fundación de pueblos. En R. Levene (Ed.) Historia de la Nación Argentina (vol. IV, pp. 307-333). Buenos Aires: Buenos Aires, Librería y Editorial El Ateneo. 
Mandrini, R. J. (1993). Guerra y paz en la frontera bonaerense durante el siglo XVIII. Ciencia Hoy, 4(23), pp. 26-35.

Mandrini, R. J. (1994). ¿Sólo de caza y robos vivían los indios? Los cacicatos pampeanos del siglo XIX. Siglo XIX, Nueva Época, 15, pp. 5-24.

Martínez Martin, C. (1994) Las reducciones de los pampas (1740-1753): aportaciones etnogeográficas al sur de Buenos Aires. Revista Complutense de Historia de América, 20, pp. 145167.

Martínez Sierra, R. (1975). El mapa de las Pampas. Buenos Aires: Ministerio del Interior, 2 tomos.

Moncaut, C. A. (1981). Reducción Jesuítica de Nuestra Señora de la Concepción de los Pampas 1740-1753. La Plata: Ministerio de Economía de la Provincia de Buenos Aires.

Nacuzzi, L. (1998). Identidades Impuestas. Tehuelches, aucas y pampas en el norte de la Patagonia. Buenos Aires: Sociedad Argentina de Antropología.

Nacuzzi, L., Lucaioli, C. y Nesis, F. (2008). Pueblos nómades en un estado colonial. Chaco, Pampa, Patagonia, Siglo XVIII. Buenos Aires: Antropofagia.

Nespolo, E. A. (2007) Las misiones jesuíticas bonaerenses del siglo XVIII, ¿¿una estrategia políticoeconómica indígena?. Revista TEFROS, 5(1). Recuperado de http://www.hum.unrc.edu.ar/ojs/index.php/tefros/issue/view/13/showToc

Outes, F. (1930) El itinerario del Rev. Padre J. Cardiel S.J. y las cartas que se le refieren. En P. J. Cardiel Diario del Viaje y Misión al Río del Sauce por fines de Marzo de 1748. Buenos Aires: Imprenta Coni.

Page, C. A. (2012). Las otras reducciones jesuíticas en la Provincia del Paraguay. Emplazamiento territorial, desarrollo urbano y arquitectónico entre los siglos XVII y XVIII. Madrid: Editorial Académica Española.

Palermo, M. A. (1991). La compleja interacción hispano-indígena en el sur argentino y chileno durante el Período Colonial. América Indígena, 1, pp. 153-192.

Palermo, M. A. (2000). A través de la frontera. Economía y sociedad indígenas desde el tiempo colonial hasta el siglo XIX. En Nueva Historia Argentina (Tomo I, pp. 344-382). Barcelona: Sudamericana

Pastells, P. P. (1948). Historia de la Compañía de Jesús en la Provincia del Paraguay. Madrid: CSIC, tomo VII (1731-1751).

Pedrotta, V. (2011). Acerca de las normas y las instituciones que deben velar por el patrimonio cultural bonaerense: el caso de la Reducción de los Indios Pampas (Castelli). Actas del II Congreso Iberoamericano y X Jornada Técnicas de Restauración y Conservación del Patrimonio. La Plata, Argentina: Comisión de Investigaciones Científicas de la Provincia de Buenos Aires.

Pedrotta, V. (2013). Reducción jesuítica Nuestra Señora de la Purísima Concepción de los Indios Pampas (Castelli, Provincia de Buenos Aires): crónicas de una década de reclamos e inacción. Revista del Museo de La Plata, 13(87), pp. 493-508. 
Pedrotta, V. (2015). Acerca de la Información hecha sobre la Reducción de los Indios Pampas que está a cargo de los RR.PP. de la Compañía de Jesús. Antiguos Jesuitas en Iberoamérica, 2(3), pp. 217-245.

Sánchez Labrador, P. J. [1772] (1936). Paraguay Catholico. Los indios Pampas, Puelches y Patagones. Buenos Aires: Viau y Zona Editores.

Zapico, H. R. (1994). El avance de la frontera sur: política y accionar del gobierno porteño en la primera mitad del siglo XVIII. En VII Encuentro de Historia Regional (pp. 243-262). Olavarría, Argentina: Comisión Municipal de Estudios Históricos. 